Citation:

Baumann, C; Timming, AR and Gollan, PJ (forthcoming) Journal of Retailing and Consumer Services.

\title{
TABOO TATTOOS? \\ A STUDY OF THE GENDERED EFFECTS OF BODY ART ON CONSUMERS' ATTITUDES TOWARD VISIBLY TATTOOED FRONT LINE STAFF
}

\begin{abstract}
The purpose of this experiment is to examine the gendered effects of body art on consumers' attitudes toward visibly tattooed employees. We analyse the reaction of 262 respondents with exposure to male and female front line staff in two distinct job contexts: a surgeon and an automobile mechanic. The results demonstrate differences on three dimensions: a) job context, b) sex of face and c) stimulus (i.e., tattooed or not). We demonstrate significant interaction effects on those three dimensions, and our findings point to the intersectionality of gender-based and tattoo-based discrimination. Consumers have a negative reaction to body art, but perceptions of tattoos on male and female front line staff differ significantly. A key marketing challenge is how to balance employees' individual rights to self-expression and at the same time cater to consumers' expectations regarding appearance of staff. Our study forms the basis for this debate that is only just emerging.
\end{abstract}

Keywords: body art, discrimination, front line staff, gender, intersectionality, tattoos 


\section{INTRODUCTION}

Gender discrimination in the workplace has been explored extensively (Darity \& Mason, 1998; Pailhe, 2000; Black \& Brainerd, 2004; Pettinger, 2005). Much of this body of literature focuses on gender as a standalone category, but there has been an increasing emphasis on intersectionality, especially pertaining to gender vis-à-vis physical characteristics that are equally subject to prejudice, such as race (Grün, 2004). Our research examines the relative weight of stigma (in this case, the presence of a visible tattoo) in forming consumer perceptions towards male and female employees in two different service sector job roles (a surgeon and an automobile mechanic) from a relationship marketing perspective. We depart from the traditional intersectionality research that focuses on gender and race (McBride, Hebson, \& Holgate, 2015) by instead shifting our attention toward the unique and underresearched intersectionality between gender and body art. We also build on a small, but emerging, literature on tattoos in the workplace (Miller, Nicols, \& Eure, 2009; Timming, 2011; Timming, 2015; Timming, Nickson, Re, \& Perrett, 2015).

Using experimental research methods, we look at consumer preferences in relation to front line employees, but we focus the study on the appearance of service sector staff from the point of view of the interaction of gender and body art, the latter of which is captured by using Photoshop to place a visible tattoo on the front line staff who are presented to the consumer respondents. Our study does not look at the effects of body art and gender on recruitment and selection outcomes since this topic has already been exhaustively researched (Timming, Nickson, Re, \& Perrett, 2015). Instead, we look at the interaction of gender-based and tattoo-based discrimination against service sector employees by potential consumers, and that is a new and previously overlooked angle. The effects we establish in our study may, however, not 
be a case of 'pure' discrimination, but rather a more innocuous consumer preference, as evidenced in Baumann and Setogawa (2015).

From a marketing perspective, the importance of our study relates to the concern of 'delivering' a consistent brand image at the front line of interactive services (Pettinger, 2004). Indeed, the 'actions' of frontline employees are a manifestation of the organization's product offering, which in turn forms a distinct brand image (Nickson et al. 2001). The performance of front line employees at the moment of interaction with the consumer is key in driving perceived service quality (Bitner et al. 1990), with personal appearance (grooming, cleanliness), dress/uniform, deportment and behaviour of the employee being crucial factors in addition to the actual 'product' itself. Zeithaml and Bitner (2000) explain that front line employees are the 'boundary spanners', establishing the link between the customer, the environment and the organization. Indeed, an interpersonal element in the interaction between customers and employees is a major determinant of customer satisfaction (Adelman et al. 1994). Schein et al. (1991), for example, found in a study of a US restaurant chain that 15 percent of customers stopped dining as a result of product dissatisfaction, but in contrast 67 percent stopped dining because of 'an indifferent attitude' of front line employees. At the end of the day, consumers' perception of front line employees often determine the formation of positive and negative emotional responses towards the individual employee, but crucially, also towards the organization overall (Liljander \& Strandvik 1995).

The interaction between front line employees and customers would likely be influenced by the impact a tattoo makes on the overall appearance of the employee in the eyes of customers. A study on tattoos is therefore important from a marketing perspective, not least since the latest statistics on tattoo prevalence show how the 
sheer number of tattooed people is too large for marketing scholars to ignore. The most recent statistics on tattoo prevalence in America show that, while in 1999, 21 per cent of respondents indicated someone in their household had a tattoo, the figure had doubled to 40 per cent in $2014^{1}$. This also means that more and more tattooed staff are now in front line positions where they have interaction with customers, and this inevitably impacts on consumer reactions. Research on that interface and the impact of tattoos is now emerging given that: a) the number of 'encounters' with tattooed front line staff is increasing, but b) the effect of tattoos is not yet well understood.

The limited literature reports, for instance, cases where employees do not convey a consistent image when a tattoo is visible during a service encounter (Pettinger, 2005; Doleac and Stein, 2013), with potentially weakening effects on brand image. The literature further demonstrates mainstream attitudes are negative towards body art (Hawkes, Senn, \& Thorn, 2004), yet big companies such as Boeing and Ford claim that non-offensive tattoos and piercings can enhance a company's image (Org, 2003). Among other contemporary companies, tattoos are becoming increasingly unproblematic across the board (Hennessey, 2013). One factor is also whether or not customers have a tattoo themselves since it has been found that people with tattoos trust tattooed salespeople more than people without tattoos (Arndt \& Glassman, 2012). Dean (2010 \& 2011) further explored negative consumer perceptions of visible tattoos on service personnel alongside the effect of age, i.e. young adult perceptions of visible tattoos.

Still, in the light of all this literature, there is an unexplored question of how companies can seek to balance employees' rights to self-expression with customers'

${ }^{1}$ http://www.nbcnews.com/nightly-news/infographic-americas-love-tattoos-grows-n95486 
expectations in respect to the aesthetics and appearance of front line staff. The present study makes a real contribution to that debate.

\section{LITERATURE REVIEW}

In the light of the present study's unique focus on intersectionality, two bodies of literature are reviewed herein. The first review looks at gender discrimination in the workplace, specifically as it pertains to the disadvantage that many women face in the labour market. The second review draws largely from the literature on stigma to illustrate how body art can result in a negative evaluation on the part of consumers in a service encounter.

\section{Gender Discrimination}

Many, but not all, studies on gender discrimination focus on the workplace, and that has been intensively discussed in the literature (e.g., Gibelman, 2000; Darity \& Mason, 1998; Meng \& Miller, 1995; Petersen \& Morgan, 1995; Knights \& Richards, 2003; Pettinger, 2005; Riach \& Rich, 2006). Gender discrimination occurs in relation to the difficulty women face in accessing favourable working conditions, e.g., securing employment, promotion or improved remuneration. In general, women are found to have more unfavourable employment situations than men across a range of workplaces and outcomes (Berik, Rodgers, \& Zveglich Jr, 2004; Blau \& Kahn, 2007), although gender discrimination can occasionally apply to men, depending on the nature of the job. Customer-service work is largely gendered as female, often due to the demands of emotion management (Pettinger, 2005). Gender discrimination also differs across country of origin (Pailhe, 2000), e.g. where certain cultural groups are more popular than others, and that effect can be magnified when gender is taken into 
account. Furthermore, gender discrimination may impact not only on employee selection, promotion and pay outcomes, but also on organisational commitment and job satisfaction (Foley, Hang-Yue, \& Wong, 2005).

Employers sometimes discriminate among employees based on the interaction of gender and other physical attributes such as race and the presence of a stigma. The interaction between gender and other unfavourable attributes led Crenshaw (1989) to introduce the term 'intersectionality', which was originally used in relation to black women's employment in the US (Crenshaw, 1991). The scope of intersectionality research has shifted from the original understanding, however. Rather than referring just to the intersection of racism and sexism (or race and gender), and thus creating a focus on the experience of black and minority ethnic women, later interpretations have emphasised its potential to refer to the intersection of a much broader range of oppressions (e.g. ageism and class) or social groupings (e.g. age, sexuality, disability) (see McBride, Hebson, and Holgate, 2015). This extended interpretation of intersectionality allows for a wider discussion of gender discrimination and how it interacts with other physical attributes that are equally subject to prejudicial views. Intersectional analysis of social divisions has thus come to occupy central spaces in both sociology, along with analyses of stratification as well as in feminist and other legal, political and policy discourses surrounding, for example, international human rights (Yuval-Davis, 2006). On this basis, it seems sensible to extend the analysis of intersectionality into other areas such as marketing, where gender discrimination may be compounded by the presence or absence of a stigma. Furthermore, whereas most of the extant literature focuses on gender discrimination at the hands of employers, the present study looks specifically at gender discrimination perpetrated by both male and female consumers. 


\section{Stigma Discrimination}

Stigma is a sociological concept (Goffman, 1963; Gray, 2002) which derives from the Greek word, fittingly, meaning 'to pierce or to tattoo' (Herek, 2002). Sociologists often break the concept down into two sub-concepts: religious stigmata, which has a positive meaning, and stigma, which has a negative connotation (Herek, 2002). Much discussion nowadays refers to stigma in a more negative connotation. Stigma in this sense creates social distance (Compton, Esterberg, McGee, Kotwicki, \& Oliva, 2006), being a marking of an individual either physically or non-physically that distinguishes him or her from normativity as defined by the rest of society.

The domain of stigma has evolved not merely about those who have a physical tattoo, referring to early meaning of the concept (Herek, 2002), but also includes those who experience unfavourable situations such as diseases: e.g., AIDS (Herek, 2002); schizophrenia (Compton et al., 2006); leprosy (Rao, Raju, Barkataki, Nanda, \& Kumar, 2008); autism (Gray, 2002); and other mental health disorders (Moses, 2010). In addition, non-physical stigma also includes homosexual behaviour (Berg and Lien, 2002; Elmslie and Tebaldi, 2007; Drydakis, 2009; Herek, Gillis, \& Cogan, 2009). Our study follows the definition of stigma as 'a brand, a mark of shame or discredit, a stain, and an identifying mark or characteristic' (Morrell, 2002). Stigma may discriminate status and power in society and society's institutions and ideological systems often legitimate such practice in the form of structural or institutional stigma (Herek et al., 2009).

Body art (i.e., piercing or tattoos) is often viewed as a stigma in most advanced industrialised societies due to its widespread attribution to those who display a marginal and sometimes deviant behaviour (Kjeldgaard \& Bengtsson, 
2005), though tattoos and piercings are increasingly found to be a more acceptable practice (Org, 2003). Body art, specifically tattooing and body piercing, has been practiced in almost every culture around the world for thousands of years (Greif, Hewitt, \& Armstrong, 1999) and the topic attracts scholars to investigate whether, for example, tattoos influence the perception of others towards individuals who have them (e.g. Hawkes et al., 2004).

The literature shows that customers engage in more avoidance behaviours with tattooed (versus) non-tattooed employees; however, there are no significant differences in purchasing behaviour based on tattoo presence (Ruggs, 2013). In contrast, Doleac and Stein (2013) found that tattoos do have a negative effect on sales. On average, younger people object less to tattoos than older people do, especially to women with tattoos (Deal, Altman, \& Rogelberg, 2010). Interestingly, women appear to experience gender discrimination in relation to tattoo attributes. Some employers require female employees to cover tattoos but do not require the same of male employees (Deal, Altman, \& Rogelberg, 2010). In the medical field, having a tattoo may not always impede a person's chance at landing a position, but rules about covering them tend to be more stringent (Hennessey, 2013).

\section{HYPOTHESES}

Our research focus is on the combined effect of gender along with a stigma interaction in the form of a visible tattoo. This hypothesised intersectionality is examined via the use of experimental psychological methods, as described later in the paper. But first, we articulate our hypotheses, each of which derived from the review of literature provided in this paper.

In essence, our study measures how likely the consumer would want the service worker to serve them in the service encounter. The basic theoretical 
framework is that there is a gender bias in services (in favour of male front line staff) and an intersectionality effect with visible tattoos (in disfavour of such). The literature reviewed above points, individually, to the fact that women and those with a tattoo are likely to experience discrimination in the workplace, and we hypothesise that similar effects would be present from a customer's perspective (i.e. the focus of our study). Thus, we present our first two hypotheses:

H1: Consumers will prefer male front line employees over female front line employees.

$\mathrm{H} 2$ : Consumers will prefer front lines employees without a visible tattoo over front line employees with a visible tattoo.

But we are also interested to discover whether 'intersectionality' is evident in these consumer ratings. Specifically, we want to unpack the extent to which tattooed women face a double stigma. Thus:

H3: Consumers will prefer male tattooed front line staff significantly over female tattooed front line staff.

\section{RESEARCH METHODS}

We employed a robust quantitative visual methodology in order to assess the study's hypotheses. This methodology involved presenting a series of photographs to respondents who were posing as consumers and asking them to rate each face on how likely they would want the employee depicted in the photograph to serve them in the front line service encounter.

\section{Experimental Stimuli}

The 'control' group is composed of eight facial photographs (four men and four women) drawn from a publically available database (www.3d.sk). We selected photos depicting a smile (instead of those with neutral expressions) on the assumption 
that, in the light of the literature on emotional labour (Bolton \& Boyd, 2003; Hochschild, 2012; Pugh, 2001), customer-facing employees would likely be under pressure to present themselves with a 'friendly-looking' face. Each control face was photographed at a $0^{\circ}$ angle and under standardised lighting. In order to promote comparability across the images, we standardised inter-pupillary distance.

We created the 'stimulus' (tattooed) group by manipulating all eight control faces using Photoshop. A circular-shaped, black 'tribal' image was selected as the tattoo stimulus. Procedurally, we superimposed the tattoo on the right side of the neck to produce a realistic tattooed version of the control faces. The same tattoo was added to all four male and all four female faces. Thus, the experiment involves eight control faces without the tattoo and eight stimulus faces with the tattoo. Because the only difference between the stimulus and control faces is the tattoo image, we were able to parcel out the pure effects of the body art on consumer preferences. Figure 1 displays a male version and a female version of our stimulus and control faces.

We were conscious prior to running the experiment about the possibility of the respondents noticing the tattoo condition as the only difference between the faces, and thus figuring out that the study was 'about' tattoos. In order to prevent the respondents from discovering the study's intent, we added another eight 'diversionary' faces into the experimental line-up. Thus, an extra four male and four female faces, including ones from different races, were added to the experiment. The only purpose of adding these extra faces was to conceal the nature of the study. Because they do not speak directly to our research questions, they are not discussed further in this paper.

\section{Data Collection}


In total, 354 respondents initially completed the instrument. There were no missing values in any of these cases. The average age of the initial sample is 36.38 years $($ s.d. $=12.46)$. Furthermore, the sample is 39.8 per cent male $(\mathrm{N}=141$ cases $)$ and 60.2 per cent female ( $\mathrm{N}=213$ cases). In terms of racial distribution, the sample is 79.1 per cent white, 7.6 per cent black, 4.2 per cent East Asian, 3.4 per cent South Asian, 0.6 per cent American Indian and 5.1 per cent of mixed race.

Following Oppenheimer, Meyvis \& Davidenko (2009), we built a unique manipulation check into the instrument in order to ensure that respondents were reading the instructions and survey items properly. The data thus were subject to screening prior to statistical analysis, resulting in the exclusion of some cases. Two items were placed strategically and randomly within the instrument in order to ascertain whether the respondent was actually paying attention, or just mindlessly completing the survey: the first was a basic math problem ('What is $8+3$ ?') and the second an item that listed out 10 hobbies, but asked the respondents to choose only the two that begin with the letter ' $r$ ' (rugby and reading). As a result of inaccurate responses across these two items, 21 cases were deleted from the dataset. This method of quality control ensures that the remaining responses are very likely valid. Furthermore, the strong statistical associations that we report in the next section corroborate that no further statistical manipulation checks were necessary. The total sample size at this point was 333 valid respondents.

One concern that arose from the demographics of the sample is the lopsided over-representation of female respondents (202 cases, versus only 131 for males). This was thought to be a problem for two methodological reasons. First, any gender differences could be distorted by the over-representation of women in the sample. Second, multi-group analyses with such unequal numbers in each category tend to be 
more susceptible to heteroscedasticity. As a result, we decided to equalise the number of male and female respondents. The final sample contained 131 male respondents and 131 female respondents that were randomly selected from the 202 valid cases of women. In other words, our final sample on which we carried out our statistical analyses is composed of 262 respondents (131 male and 131 female). Although this might be considered a modest sample size in some social science disciplines, in the context of experimental psychology, this is considered a very large sample.

The participants completed the survey through a popular online crowdsourcing platform. They were paid a nominal fee of \$0.11US to incentivise timely completion of the instrument. Informed consent was given by all respondents prior to completing the questionnaire. Two experiments were carried out back-to-back.

In Experiment 1, respondents were presented with the following instructions: 'Imagine that you need to visit the hospital for a routine surgery. The doctor calls you back for your first consultation. We will now show you some photographs of doctor's faces. How likely would you be to want this person to be your doctor?'. The eight control faces, eight stimulus faces and eight diversionary faces were then presented to the respondents in random order and they were asked to rate them on a scale of 1-7 (where 1='not at all likely' and 7='extremely likely' that they would want that person to be their doctor). The presentation of faces was randomised in order to prevent the respondents from identifying a pattern.

In Experiment 2, respondents were presented with the following instructions: 'Now imagine that you've damaged your car and so you take it into a mechanic to get it fixed. We're going to show you some faces of mechanics. How likely are you to want them to fix your car?'. The same 24 faces were presented to the respondents, again in randomised order. They were asked to rate the faces on a scale of 1-7 (where 
$1=$ 'not at all likely' and 7='extremely likely' that they would want that person to fix their car).

These two occupations, or roles, were selected into the experimental design for two main reasons. First, we sought occupations that would speak to the gendered effects that we hypothesised. Both surgeons and mechanics have traditionally tended to be male-dominated occupations, so we were keen to unpack empirically the extent of discrimination against especially female front line staff in both contexts. Second, we also sought occupations that could reasonably be expected to have varying degrees of acceptance of body art. Whilst visible body art on medical personnel has already been shown to be perceived negatively (Newman, Wright, Wrenn \& Bernard, 2005), one might expect that tattoos in automotive repair services are more widely embraced. In short, these two occupations are ideally suited to evaluate the intersectionality of gender and body art at work.

Analysis

In light of the repeated-measures nature of the experiment, a mixed design ANOVA was indicated. The statistical analyses aimed to unpack the extent to which ratings of the faces varied by job context (doctor vs. mechanic), sex of face (male vs. female), presence of the stimulus (tattoo vs. no tattoo) and sex of respondent (male vs. female). Thus, a $2 \mathrm{X} 2 \mathrm{X} 2 \mathrm{X} 2$ ANOVA is modelled statistically with interaction effects. Sex of respondent was included in the analysis as a between-subjects variable.

\section{RESULTS}

Table 1 reports the results of the main effects of the mixed design ANOVA. These main effects, it should be noted, do not speak directly to our hypotheses, all of 
which can only be accepted or rejected by examining the interaction effects reported from the following paragraph. The main effects are only reported here in order to set the stage for the interactions. There was a main effect of job context, with the respondents rating all faces higher when presented as mechanics $(\mathrm{M}=4.04, \mathrm{SE}=.07)$ than when presented as surgeons $(\mathrm{M}=3.71, \mathrm{SE}=.07 ; \mathrm{F}(1,260)=29.65, p=.000$, $\left.\eta_{\mathrm{p}}{ }^{2}=.102\right)$. In other words, all faces, both men and women with and without tattoos, were viewed more positively as mechanics than surgeons. There was a main effect of sex of face as well, with all male faces rated higher $(\mathrm{M}=4.17, \mathrm{SE}=.07)$ than all female faces $\left(\mathrm{M}=3.58 ; \mathrm{SE}=.07 ; \mathrm{F}(1,260)=109.01, p=.000, \eta_{\mathrm{p}}{ }^{2}=.295\right)$. This finding indicates that, regardless of job context and presence (or not) of a tattoo, the male faces were viewed generally more favourably than the female faces. There was also a main effect of stimulus, with all tattooed faces being rated lower $(\mathrm{M}=3.57, \mathrm{SE}=.07)$ than original faces $\left(\mathrm{M}=4.18, \mathrm{SE}=.06 ; \mathrm{F}(1,260)=157.83, p=.000, \eta_{\mathrm{p}}{ }^{2}=.378\right)$. This finding suggests that tattoos in general are associated with reduced consumer ratings. Interestingly, the gender of the participant was not statistically significant in the main effects. In other words, the 131 men and 131 women participating in the experiment were remarkably consistent in how they rated the faces overall.

Table 2 reports the results of a significant interaction between job context and sex of face $\left(\mathrm{F}(1,260)=241.89, p=.000, \eta_{\mathrm{p}}{ }^{2}=.482\right)$. The male surgeons were rated lower $(\mathrm{M}=3.65, \mathrm{SE}=.07)$ than female surgeons $(\mathrm{M}=3.77, \mathrm{SE}=.08)$, regardless of the presence of a tattoo. Thus, consumers have a slight preference for women doctors. On the other hand, male mechanics were rated significantly higher $(\mathrm{M}=4.68, \mathrm{SE}=.07)$ than female mechanics ( $M=3.39, \mathrm{SE}=.09)$, suggesting an unambiguous preference for men when it comes to fixing cars. Interestingly, the three way interaction between job context, sex 
of face and participant gender is statistically insignificant, thus implying no difference between male and female consumer attitudes on this question.

Table 3 reports the results of a significant interaction between job context and stimulus $\left(\mathrm{F}(1,260)=144.55, p=.000, \eta_{\mathrm{p}}{ }^{2}=.357\right)$. The tattooed surgeons were rated much lower $(\mathrm{M}=3.20, \mathrm{SE}=.08)$ than the surgeons without a tattoo $(\mathrm{M}=4.22, \mathrm{SE}=.07)$. The tattooed mechanics were also rated lower $(\mathrm{M}=3.94, \mathrm{SE}=.08)$ than the mechanics without a tattoo $(\mathrm{M}=4.14, \mathrm{SE}=.07)$, but the margin of difference is much smaller. This means that the tattoo is just a slight liability for a mechanic, but a major liability for a surgeon. When participant sex is factored into the equation, resulting in a three-way interaction, the result is statistically significant $\left(\mathrm{F}(1,260)=7.85, p=.005, \eta_{\mathrm{p}}{ }^{2}=.029\right)$, but weak, as indicated by the partial eta squared. The results of this three-way interaction point to a greater degree of tolerance and acceptance on the part of female consumers of both tattooed surgeons and mechanics in comparison to male consumers.

Table 4 reports the results of a significant interaction between sex of face and stimulus $\left(\mathrm{F}\left(1,260=24.65, p=.000, \eta_{\mathrm{p}}{ }^{2}=.087\right)\right.$. Overall, male faces with a tattoo scored lower $(\mathrm{M}=3.81, \mathrm{SE}=.08)$ than male faces without a tattoo $(\mathrm{M}=4.52, \mathrm{SE}=.07)$. Female faces with a tattoo also scored lower $(\mathrm{M}=3.32, \mathrm{SE}=.08)$ than female faces without a tattoo $(M=3.84, S E=.07)$. Using these same statistics, it is also worth noting that male faces with a tattoo scored higher than female faces with a tattoo and roughly the same as female faces without a tattoo. In other words, gender seems to be a greater liability than the tattoo, but tattooed women appear to be doubly stigmatised. When participant sex is factored into a three-way interaction (sex of face*stimulus*participant sex), the results are statistically significant $\left(\mathrm{F}(1,260)=5.87, p=.016, \eta_{\mathrm{p}}{ }^{2}=.022\right)$, but again fairly weak. They suggest that women consumers rate the tattooed faces (both male and female) slightly more positively than male consumers. 
Table 5 reports the results of a statistically significant three-way interaction effect among job context, sex of face and stimulus $\left(\mathrm{F}(1,260)=4.71, p=.031, \eta_{\mathrm{p}}{ }^{2}=.018\right)$. Male surgeons with a tattoo were rated lower $(\mathrm{M}=3.11, \mathrm{SE}=.09)$ than male surgeons without a tattoo $(\mathrm{M}=4.20, \mathrm{SE}=.08)$. Female surgeons with a tattoo were rated lower $(\mathrm{M}=3.28, \mathrm{SE}=.09)$ than female surgeons without a tattoo $(\mathrm{M}=4.25, \mathrm{SE}=.08)$. Equally, the male mechanics with a tattoo were rated lower $(\mathrm{M}=4.51, \mathrm{SE}=.08)$ than the male mechanics without a tattoo $(\mathrm{M}=4.85, \mathrm{SE}=.07)$. The female mechanics with a tattoo were rated only slightly lower $(\mathrm{M}=3.37, \mathrm{SE}=.10)$ than the female mechanics without a tattoo $(\mathrm{M}=3.42, \mathrm{SE}=.10)$. In order to accentuate these highly gendered effects, Figures 2 and 3 display graphically the relationship between job context and stimulus for male faces and female faces, respectively. Clearly, both figures show that men benefit from not having a tattoo in both job contexts, whereas for women mechanics, the tattoo is virtually irrelevant next to the disadvantage of their gender.

Using the same statistics reported in Table 5, some interesting results emerge. For example, female surgeons (both tattooed and not tattooed) scored higher than the corresponding male surgeons. Among surgeons, the highest consumer rating belongs to the female doctor without a tattoo $(M=4.25)$, followed by the male doctor without a tattoo $(M=4.20)$, the female doctor with a tattoo $(M=3.28)$ and, lastly, the male doctor with a tattoo $(M=3.11)$. Thus, the respondents, in aggregate, have a preference for female surgeons. Among mechanics, the findings suggest that being female is a much greater liability than having a tattoo. The highest rating is assigned to the male mechanic with no tattoo $(M=4.85)$, followed by the male mechanic with a tattoo $(M=4.51)$. The third highest rating is the female mechanic without a tattoo $(M=3.42)$, followed closely by the female mechanic with a tattoo $(M=3.37)$. In other words, though the tattoo is still a stigma among mechanics, the more important stigma is 
being a woman. This finding is reflected in the magnitude of the difference in ratings between female mechanics with and without a tattoo (mean difference $=-.05$ ). Thus, consumers do not appear to care whether the woman mechanic has a tattoo or not; they simply do not want a woman working on their car.

Finally, it is worth noting that the four-way interaction of job context, sex of face, stimulus and participant gender was not statistically significant $(F(1,260)=.058$, $\left.p=.810, \eta_{\mathrm{p}}{ }^{2}=.000\right)$. That is to say that the social judgements described in the preceding paragraph do not differ between male and female consumers. Both men and women equally favour female surgeons and discriminate against female mechanics. They also both equally view the tattoo as a double stigma in both job contexts, although, among mechanics, being female is comparatively much worse than having a visible tattoo. Conversely, among surgeons, having a visible tattoo is comparatively much worse than being a woman.

\section{DISCUSSION AND CONCLUSIONS}

This study makes a unique contribution to our understanding of the interplay of gender and body art in front line service employees and how they are perceived by customers in two very different job contexts. Some of the results are encouraging from a feminist perspective, whilst others, sadly, corroborate the continuing challenges that many women face in the labour market. For example, it was refreshing to see that our male and female respondents statistically significantly preferred a female surgeon to a male surgeon, even though the experiment also found that both male and female consumers are equally antagonistic toward female mechanics. Thus, H1 is only partially confirmed. The study also found that the tattoo was a significant liability for service employees in both job contexts, thus confirming $\mathrm{H} 2$. However, on 
the question of intersectionality, we found no evidence and thus reject H3. Not only was the tattooed female surgeon rated higher than the tattooed male surgeon, but also the presence of a tattoo on a female mechanic did not even figure into consumers' perceptions. In other words, the data suggest that whether or not a woman mechanic displays a visible tattoo is irrelevant: consumers (both male and female) simply do not want a woman working on their cars. It is remarkable that in most of our interaction models, the gender of our respondents was not statistically significant. That is to say that male and female consumers hold roughly the same gendered views on body art in the workplace.

What our results mean for research is that future consumer interaction models should seek to include the dimensions we have tested and found to impact consumer perceptions of front line employees. Job context matters, and while we have looked at the medical vis-à-vis automotive professions, future research and modelling should include other services such as education, financial services or more generic industries such as cleaning. Sex of face (male vis-à-vis female) was also a relevant factor in our study, and whilst gender typically has been explored extensively in the literature (Gibelman, 2000; Darity \& Mason, 1998; Meng \& Miller, 1995; Petersen \& Morgan, 1995; Knights \& Richards, 2003; Pettinger, 2005; Riach \& Rich, 2006), future researchers could probe further intersectionalities of gender in relation to the front line employee to see if they can identify an effect. Our study would also have to be extended to a larger service experience context. Baker (1986) presented an often referred to typology that groups the elements of store/service environment into three categories:

- Social factors: people in the store such as customers and employees. 
- Design factors: visual elements such as layout, color, clutter and cleanliness.

- Ambient factors: non-visual elements such as smells, sound and lighting effects.

Naturally, a visible tattoo and the gender of service staff are only two of the many atmospheric elements outlined above that will influence customers' overall perception of a service. We have demonstrated the effects of tattoo and gender overall, but further research should probe the relative importance of these factors in a larger service context, testing additional atmospheric elements.

The key focus of our study was the effect of a stimulus (tattooed face vis-à-vis original face) in relation to the aforementioned dimensions, and tattoos were clearly a driving factor for front line staff perception in our experiments. Future research could explore these effects more in relation to tattoo size, type and location on the body, to name a few areas that warrant further exploration. There could also potentially be more inherent meaning of tattoos of different genres (such as political, ideological or religious messages). Thus, future research should seek to examine the effect of different genres of tattoos (Timming, 2015) on consumer preferences and attitudes.

The practical implications of our work pertain mainly to an emerging debate on the balance between employees' rights to self-expression and employers' rights to regulate employee appearance. As such, there are two perspectives:

\section{Employers' rights to regulate employee appearance}

There are quite substantial differences in terms of legal and cultural environments in relation to the degree that employers can prescribe and enforce personal appearance (grooming, cleanliness), dress/uniform, deportment and behaviour policy for their employees. For example in the airline industry, strict 
standards in terms of visual presentation (uniform, hair, grooming) are common for cabin crew, albeit differences in the law have varying impacts on formal requirements such as age (from commencement of service to retirement), to height and weight. What is acceptable in one country, is illegal and perceived as discrimination in another; what is acceptable at one airline, is unthinkable at another. As such there are substantial within and between industry and country differences when it comes to policy regarding the appearance and behaviour of front line employees.

While from a legal perspective, courts in Western countries often conclude that the management has the 'right to choose and manage', shifting the power - more or less - to the employer side. Employers can issue and enforce formal policy as long as they are not discriminatory. Naturally, however, there is also an informal 'policy' of what is acceptable appearance and behaviour at the workplace, a so called unwritten code of conduct and appearance.

Violations of formal policy or non-compliance with informal standards will likely affect promotion options for existing employees, and reduce chances of employment in the first place if detected during the recruitment process. Alternatively, non-conforming employees would often be reassigned to a new role, one that is non customer facing. In order to avoid such conflict, service firms should set clear standards at recruitment and staff development events in terms of formal and informal expectations in relation to grooming, cleanliness and personal appearance. A transparent policy is needed that makes expectations explicit (i.e. acceptable minimal standards), especially in relation to customer service roles.

\section{Employees' rights to self-expression}


Employees have a choice to accept work conditions (including policy in regards to appearance and behaviour), take legal action against their employer if there is a dispute, or defect and seek new employment if they feel employer's expectations are not aligned with their personality. There is also a need for employees to familiarise themselves with the formal and informal expectations at their workplace, understanding that non-compliance may at best be career limiting, especially in front line functions, or at worst result in disciplinary action from the employer, including legal action. Understanding these explicit and implicit rules is often challenging, and hence our call to make such policy transparent to all stakeholders.

There are services where visible tattoos are not uncommon and largely accepted, for example in Western police force (e.g. Australia, UK, USA), but unthinkable in the East Asian region (China, Japan, Korea, Taiwan). Ultimately, visible tattoos often serve the purpose to get attention and sometimes also provoke, and that has to be understood in the context of a service role. Employees hence need to consider visible tattoos carefully, and understand that size and type of tattoo (violent, sexual, anti-social themes) may reduce employment options or indeed be career hindering in the services sector.

Our paper does not present a solution to the conflicts and complexities outlined above on the balance between employees' rights to self-expression and employers' rights to regulate employee appearance, of course, but rather offers empirical evidence on the specific impact of tattoos, and we aspired to position that issue in the larger context of the overall service environment. It is clear from our study that consumers are fairly sceptical towards tattoos, so the simple answer would ostensibly be to implement a workplace policy that instructs front line employees to 
hide their tattoos, or not to hire tattooed employees in the first place. However, such drastic action could be viewed as impeding workers' rights to self-expression, and too drastic a policy could result in court cases based on 'lookism' (Warhurst, van den Broek, Nickson, \& Hall, 2012).

In some way, our study unpacks a dilemma for marketers: customers do not want to see tattoos on front line staff, but on the other hand, front line staff could hardly be prevented from a) having them in the first place and b) more or less displaying them at work. From a brand management perspective, this could be viewed as a challenge, since the uniform of front line staff and instructed behaviour and communication contribute to a stream-lined brand image, but tattoos may distract from that brand image, and in some cases even 'deduct' brand value and/or equity if the tattoo is indeed viewed as disturbing. Interestingly, there could also be an interplay of brand logos since there is an increasing popularity of logo tattoos (Orend \& Gagné, 2009) motivated by brand loyalty and self-identification with a brand. This also means that a tattooed logo could be adding or deducting 'value' to the service experience depending on the match, e.g. it could be the same logo as the employer, one of a competitor, or an unrelated brand logo.

Importantly, we would like to offer some directions for future research. The perception of front line staff by consumers is an important part of the overall service experience, yet it is an under-researched area in general, and in particular how certain stigma impact the service experience. The actual human experience between staff and customers matters, and we know from recent research that ethnicity plays a key role, which we did not capture in our study. More precisely, ethnicity preferences have been established as the 'country of origin of service staff' (COSS) effect (Baumann \& Setagowa, 2015). Significant differences were found in preferences for the ethnicity 
of service staff with many consumers, regardless of their ethnicity, preferring service staff of the same ethnicity. This also means that there was a gap between preferences for consumers' own ethnicity and preferences for others, with medical services having the strongest effects - an area also under investigation in our study where we looked at surgeons. Baumann \& Setagowa (2015) explained the 'country of origin of service staff' (COSS) effect based on theories of country of origin, animosity, homophily and language. We propose that these theories should be probed in the context of the intersectionality of gender-based and tattoo-based discrimination. In other words, the COSS effect should be tested for potential moderating effects in relation to job context (surgeon vis-à-vis mechanic as well as other professions), sex of face (male vis-à-vis female) and stimulus (tattooed face vis-à-vis original face). It is not unlikely that there would be effects for ethnicity of service staff in relation to their job, gender and stimulus such as tattoos that would likely impact how consumers perceive their service delivery, and that in turn likely affects customer satisfaction and loyalty. 
FIGURE 1: Examples of Stimulus and Control Images
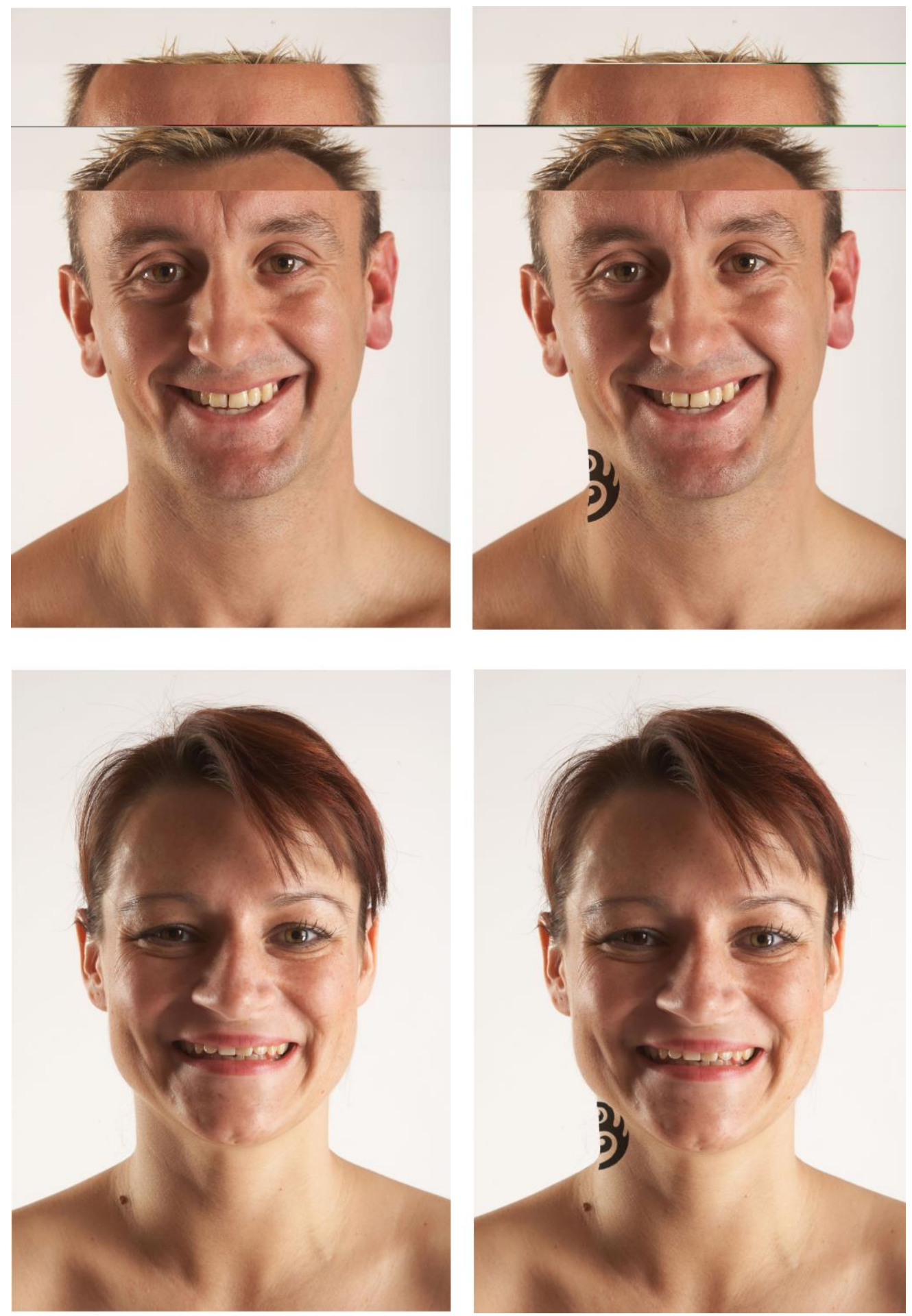
TABLE 1: Summary of Main Effects of the 2X2X2X2 Mixed Design ANOVA

\begin{tabular}{|c|c|c|c|c|c|c|}
\hline & Effect type & Mean rating (SE) & Mean rating difference & $\mathbf{F}$ & $\mathbf{p}$ & $\eta_{p}^{2}$ \\
\hline $\begin{array}{l}\text { Job Context } \\
\text { (surgeon; mechanic) }\end{array}$ & Within-subjects & $\begin{array}{l}\text { Surgeon: } 3.71(.07) \\
\text { Mechanic: } 4.04(.07)\end{array}$ & -.33 & 29.65 & .000 & .102 \\
\hline $\begin{array}{l}\text { Sex of Face } \\
\text { (male; female) }\end{array}$ & Within-subjects & $\begin{array}{l}\text { Male: } 4.17(.07) \\
\text { Female: } 3.58(.07)\end{array}$ & .59 & 109.01 & .000 & .295 \\
\hline $\begin{array}{l}\text { Stimulus } \\
\text { (tattooed face; original } \\
\text { face) }\end{array}$ & Within-subjects & $\begin{array}{l}\text { Tattoo: } 3.57(.07) \\
\text { No tattoo: } 4.18(.06)\end{array}$ & -.61 & 157.83 & .000 & .378 \\
\hline $\begin{array}{l}\text { Participant Gender } \\
\text { (men, women) }\end{array}$ & Between-subjects & $\begin{array}{l}\text { Male Consumer: } 3.89 \text { (.09) } \\
\text { Female Consumer: } 3.86(.09)\end{array}$ & .03 & .06 & .809 & .000 \\
\hline
\end{tabular}


TABLE 2: Two-Way Interaction Effect between Job Context and Sex of Face

Male faces

Surgeon

$3.65(.07)$

Female faces

$3.77(.08)$

Mean difference

$-.12$

$241.89 \quad .000$

.482

Mechanic

4.68 (.07)

3.39 (.09)

1.29 
TABLE 3: Two-Way Interaction Effect between Job Context and Stimulus

\section{Tattooed faces}

$3.20(.08)$

Surgeon

Mechanic
Original faces

$4.22(.07)$
Mean difference

$-1.02$ $\begin{array}{llll}144.55 & .000 \quad .357\end{array}$

\section{$\mathbf{F} \quad \mathbf{p} \quad \boldsymbol{\eta}_{\mathbf{p}}^{2}$}

(1)

57


TABLE 4: Two-Way Interaction Effect between Sex of Face and Stimulus

\section{Tattooed faces \\ Original faces}

$3.81(.08)$

Male faces

$4.52(.07)$
$-.71$

24.65

.000

.087

\section{Female faces}

$3.32(.08)$

$3.84(.07)$

$-.52$ 
TABLE 5: Three-Way Interaction Effect among Job Context, Sex of Face and Stimulus

\begin{tabular}{|c|c|c|c|c|c|c|c|}
\hline & & Tattooed faces & Original faces & Mean difference & $\mathbf{F}$ & $\mathbf{p}$ & $\eta_{p}^{2}$ \\
\hline \multirow[t]{3}{*}{ Surgeon } & Male faces & $3.11(.09)$ & $4.20(.08)$ & -1.09 & & & \\
\hline & Female faces & $3.28(.09)$ & $4.25(.08)$ & -.97 & & & \\
\hline & & & & & 4.71 & .031 & .018 \\
\hline \multirow[t]{2}{*}{ Mechanic } & Male faces & $4.51(.08)$ & $4.85(.07)$ & -.34 & & & \\
\hline & Female faces & $3.37(.10)$ & $3.42(.10)$ & -.05 & & & \\
\hline
\end{tabular}


FIGURE 2: Graphical Representation of Relationship between Job Context and $\underline{\text { Stimulus for Male Faces }}$

\section{Male Faces}

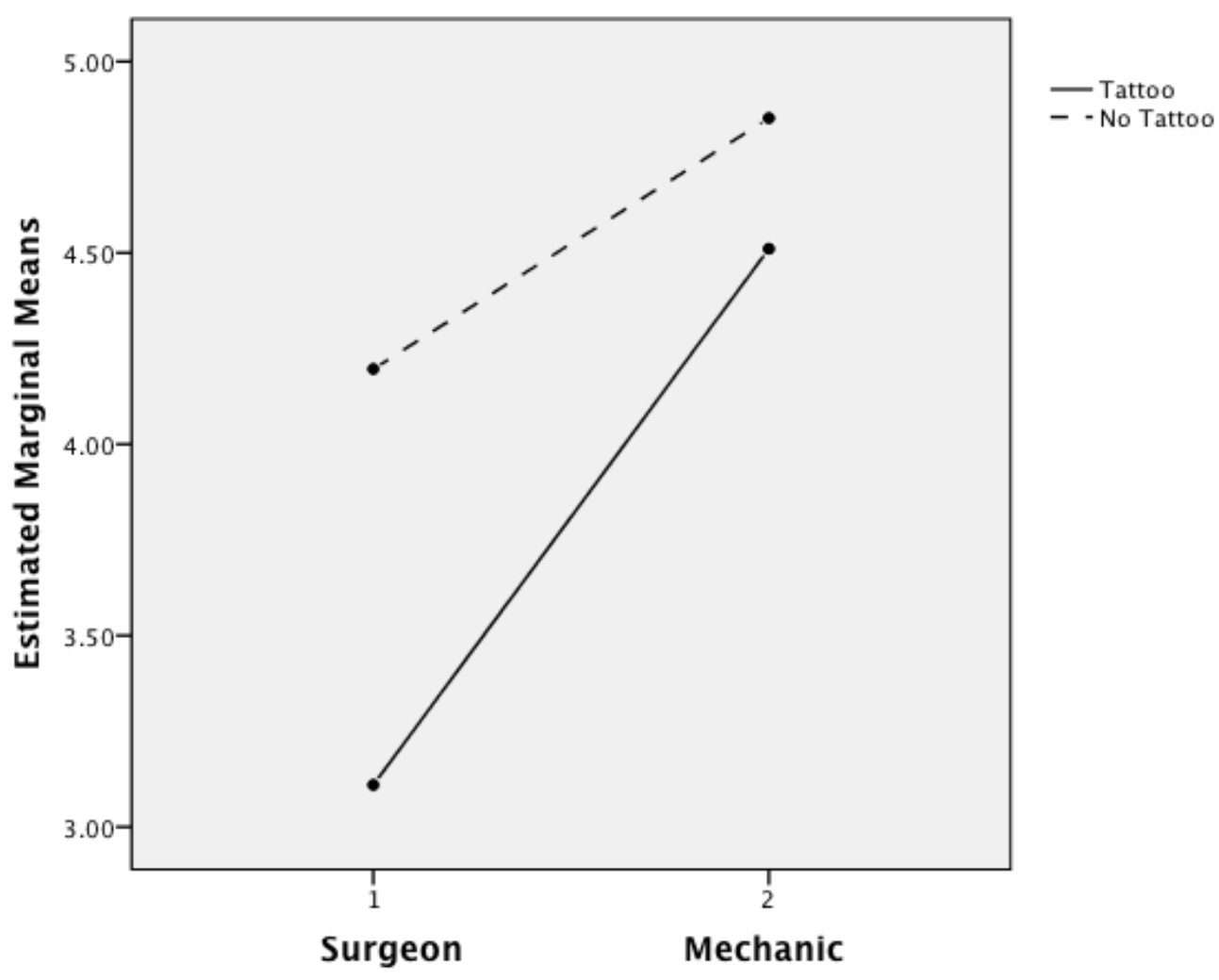


FIGURE 3: Graphical Representation of Relationship between Job Context and Stimulus for Female Faces

Female Faces

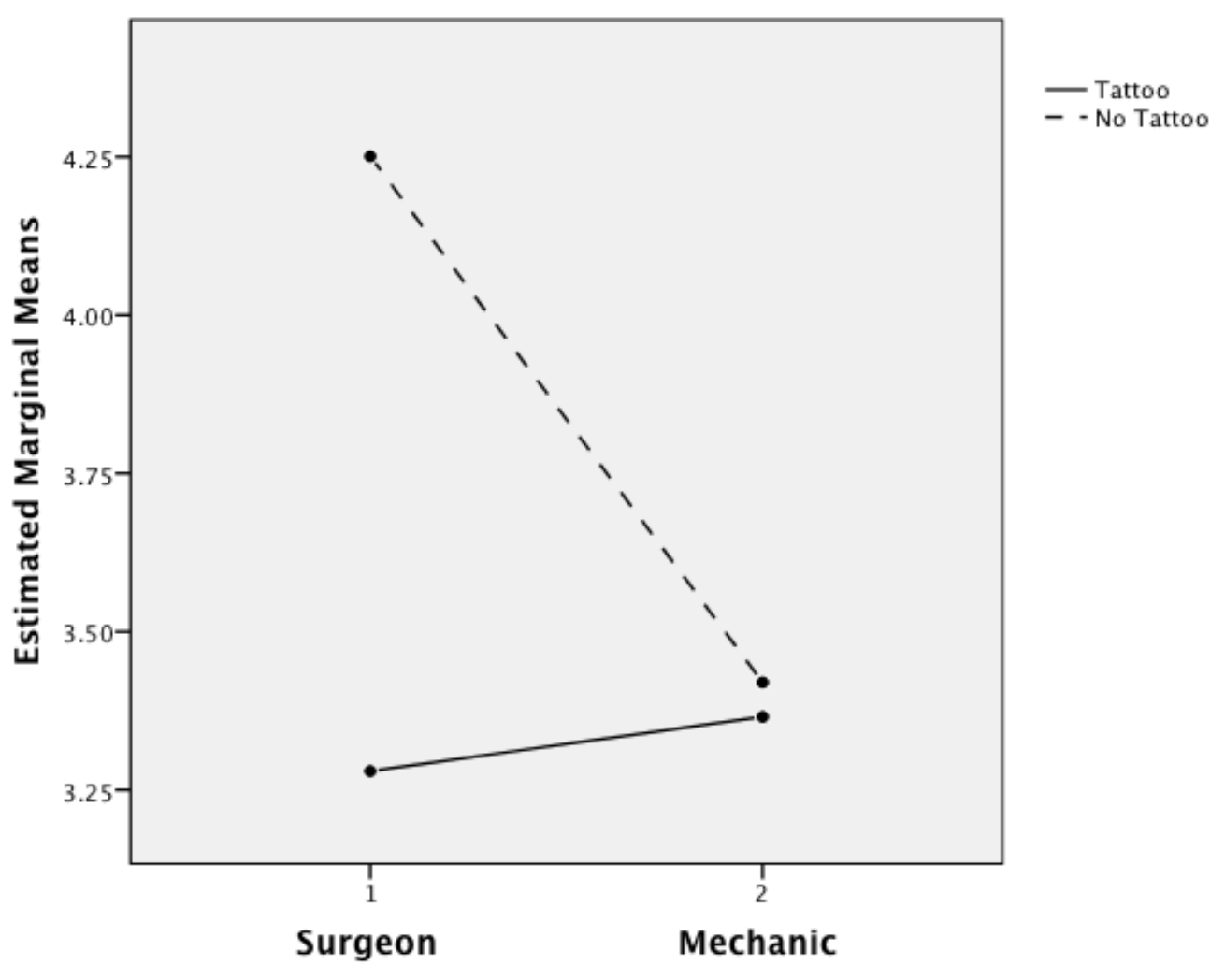




\section{References}

Adelman, M. B., Ahuvia, A., \& Goodwin, C. (1994). Beyond smiling: social support and service quality. Service quality: New directions in theory and practice, $139-71$.

Arndt, A. D. and Glassman, M. (2012) What Tattoos Tell Customers About Salespeople: The Role of Gender Norms. Marketing Management Journal, 22(1): 50-65.

Baker, J. (1986). The role of the environment in marketing services: the consumer perspective. The services challenge: Integrating for competitive advantage, 1(1), 79-84.

Baumann, C., \& Setogawa, S. (2015). Asian ethnicity in the West: preference for Chinese, Indian and Korean service staff. Asian Ethnicity, 16(3), 380-398, 119.

Berg, N., \& Lien, D. (2002). Measuring the effect or sexual orientation on income: Evidence of discrimination? Contemporary Economic Policy, 20(4), 394.

Berik, G., van der Muelen Rodgers, Y., \& Zveglich Jr, J. E. (2004). International Trade and Gender Wage Discrimination: Evidence from East Asia. Review of Development Economics, 8(2), 237-254.

Bitner, M. J. (1990) Evaluating service encounters: the effects of physical surroundings and employee responses, The Journal of Marketing, 69-82.

Black, S. E., \& Brainerd, E. (2004). Importing Equality? The Impact of Globalization on Gender Discrimination. Industrial and Labor Relations Review, 57(4), 540559 .

Blau, F. D., \& Kahn, L. M. (2007). The Gender Pay Gap: Have Women Gone as Far as They Can? Academy of Management Perspectives, 21(1), 7-23.

Bolton, S. C., \& Boyd, C. (2003). Trolley dolly or skilled emotion manager? Moving on from Hochschild's Managed Heart. Work, Employment \& Society, 17(2), 289-308.

Compton, M. T., Esterberg, M. L., McGee, R., Kotwicki, R. J., \& Oliva, J. R. (2006). Brief reports: crisis intervention team training: changes in knowledge, attitudes, and stigma related to schizophrenia. Psychiatric Services, 57(8), 1199-1202.

Crenshaw, K. (1989). Demarginalizing the intersection of race and sex: A black feminist critique of antidiscrimination doctrine, feminist theory and antiracist politics. U. Chi. Legal F., 139. 
Crenshaw, K. (1991). Mapping the margins: Intersectionality, identity politics and violence against women of color. Stanford Law Review, 43(6), 1241-1299.

Deal, J. J., Altman, D. G., \& Rogelberg, S. G. (2010). Millennials at work: What we know and what we need to do (if anything). Journal of Business and Psychology, 25(2), 191-199.

Dean, D. H. (2010) Consumer perceptions of visible tattoos on service personnel. Managing Service Quality 20(3): 294-308.

Dean, D. H. (2011) Young adult perception of visible tattoos on a white-collar service provider. Young Consumers 12(3): 254-264.

Doleac, J. L., \& Stein, L. C. D. (2013). The visible hand: Race and online market outcomes. The Economic Journal, 123(572), 469-492.

Drydakis, N. (2009). Sexual orientation discrimination in the labour market. Labour Economics, 16(4), 364-372.

Elmslie, B., \& Tebaldi, E. (2007). Sexual Orientation and Labor Market Discrimination. Journal of Labor Research, 28(3), 436-453.

Foley, S., Hang-Yue, N., \& Wong, A. (2005). Perceptions of Discrimination and Justice Are There Gender Differences in Outcomes? Group \& Organization Management, 30(4), 421-450.

Gibelman, M. (2000). The nonprofit sector and gender discrimination. Nonprofit Management and Leadership, 10(3), 251-269.

Goffman, E. (1963). Stigma: Notes on the Management of Spoiled Identity. New York: Simon \& Schuster.

Gray, D. E. (2002). 'Everybody just freezes. Everybody is just embarrassed': Felt and enacted stigma among parents of children with high functioning autism. Sociology of Health \& Illness, 24(6), 734-749.

Greif, J., Hewitt, W., \& Armstrong, M. L. (1999). Tattooing and Body Piercing: Body Art Practices among College Students. Clinical Nursing Research, 8(4), 368385.

Grün, C. (2004). Direct and indirect gender discrimination in the South African labour market. International Journal of Manpower, 25(3/4), 321-342.

Hawkes, D., Senn, C. Y., \& Thorn, C. (2004). Factors that influence attitudes toward women with tattoos. Sex Roles, 50(9-10), 593-604. 
Hennessey, R. (2013). Tattoos no longer a kiss of death in the workplace, Forbes, Feb 27.

Herek, G. M. (2002). Thinking about AIDS and stigma: A psychologist's perspective. The Journal of Law, Medicine \& Ethics, 30(4), 594-607.

Herek, G. M., Gillis, J. R., \& Cogan, J. C. (2009). Internalized stigma among sexual minority adults: Insights from a social psychological perspective. Journal of Counseling Psychology, 56(1), 32.

Hochschild, A. R. (2012). The managed heart: Commercialization of human feeling: Univ of California Press.

Darity, W. A., \& Mason, P. L. (1998). Evidence on Discrimination in Employment: Codes of Color, Codes of Gender. The Journal of Economic Perspectives, 12(2), 63-90.

Kjeldgaard, D., \& Bengtsson, A. (2005). Consuming the Fashion Tattoo. Advances in Consumer Research, 32(1), 172-177.

Knights, D., \& Richards, W. (2003). Sex Discrimination in UK Academia. Gender, Work \& Organization, 10(2), 213-238.

Kuhn, P., \& Shen, K. (2013). Gender Discrimination in Job Ads: Evidence from China. The Quarterly Journal of Economics, 128(1), 287-336.

Liljander, V., \& Strandvik, T. (1995) The nature of customer relationships in services, Advances in Services Marketing and Management, 4(141), 67.

McBride, A., Hebson, G., \& Holgate, J. (2015). Intersectionality: Are we taking enough notice in the field of work and employment relations? Work, Employment \& Society, 29(2), 331-341.

Meng, X., \& Miller, P. (1995). Occupational segregation and its impact on gender wage discrimination in China's rural industrial sector. Oxford Economic Papers, 136-155.

Miller, B. K.; Nicols, K. M., \& Eure, J. (2009). Body art in the workplace: Piercing the prejudice? Personnel Review, 38(6), 621-640.

Morrell, M. J. (2002). Stigma and epilepsy. Epilepsy \& Behavior, 3(6, Supplement 2), 21-25.

Moses, T. (2010). Being treated differently: Stigma experiences with family, peers, and school staff among adolescents with mental health disorders. Social Science \& Medicine, 70(7), 985-993. 
Newman, A. W.; Wright, S. W.; Wrenn, K. D. and Bernard, A. (2005) Should Physicians Have Facial Piercings? Journal of General Internal Medicine, 20(3), 213-218.

Nickson, D. P., Warhurst, C., Witz, A., \& Cullen, A. M. (2001) The importance of being aesthetic: Work, employment and service organization.

Oppenheimer, D. M.; Meyvis, T. and Davidenko, N. (2009) Instructional manipulation checks: Detecting satisficing to increase statistical power. Journal of Experimental Social Psychology, 45, 867-872.

Orend, A. and Gagné, P. (2009) Corporate Logo Tattoos and the Commodification of the body. Journal of Contemporary Ethnography 38(4): 493-517.

Org, M. (2003). Tattoos and piercings come out at the office, Wall Street Journal.

Pailhe, A. (2000). Gender discrimination in Central Europe during the systemic transition. Economics of Transition, 8(2), 505.

Palermo, G. B. (2004). Tattooing and Tattooed Criminals. Journal of Forensic Psychology Practice, 4(1), 1-25.

Petersen, T., \& Morgan, L. A. (1995). Separate and unequal: Occupationestablishment sex segregation and the gender wage gap. American Journal of Sociology, 329-365.

Pettinger, L. (2004). Brand culture and branded workers: Service work and aesthetic labour in fashion retail. Consumption Markets \& Culture, 7(2), 165-184.

Pettinger, L. (2005). Gendered Work Meets Gendered Goods: Selling and Service in Clothing Retail. Gender, Work \& Organization, 12(5), 460-478.

Pugh, S. D. (2001). Service with a smile: Emotional contagion in the service encounter. Academy of management journal, 44(5), 1018-1027.

Rao, P., Raju, M., Barkataki, A., Nanda, N., \& Kumar, S. (2008). 5 Extent and Correlates of Leprosy Stigma in Rural India. Indian journal of leprosy, 80(2), 167.

Riach, P. A., \& Rich, J. (2006). An experimental investigation of sexual discrimination in hiring in the English labor market. Advances in Economic Analysis \& Policy, 5(2).

Ruggs, E. (2013). The Influence of Employee Inkings on Consumer Behavior: Booed, Eschewed, and Tattooed. Rice University. 
Schein, E. H., FROST, P. J., Moore, L. F., Louis, M. R., Lundberg, C. C., \& Martin, J. (1991). Reframing organizational culture. Reframing organizational culture.

Spears Brown, C., \& Bigler, R. S. (2004). Children's perceptions of gender discrimination. Developmental Psychology, 40(5), 714.

Timming, A. R. (2011) What Do Tattoo Artists Know about HRM? Recruitment and Selection in the Body Art Sector. Employee Relations, 33(5): 570-584.

Timming, A. R. (2015). Visible tattoos in the service sector: A new challenge to recruitment and selection. Work, Employment \& Society, 29(1), 60-78.

Timming, A. R.; Nickson, D.; Re, D., \& Perrett, D. (2015). What do you think of my ink? Assessing the effects of body art on employment chances. Human Resource Management.

Warhurst, C.; van den Broek, D.; Nickson, D. and Hall, R. (2012). Great expectations: gender, looks and lookism at work. International Journal of Work, Organization and Emotion, 5(1), 72-90.

Yuval-Davis, N. (2006). Intersectionality and feminist politics. European Journal of Women's Studies, 13(3), 193-209.

Zeithaml, V.A. and Bitner, M.J. (2000), Services Marketing: Integrating Customer Focus Across the Firm, McGraw - Hill, New York, NY. 